\title{
Physical Characterization and Microstructure Evaluation of Titanium Dioxide Semiconductor Discs Processed with Binders
}

\author{
Shahida Begum*, MNM Ansari, LM Keong and T Velloo \\ Centre for Advance Materials, Department of Mechanical Engineering, University Tenaga Nasional, Putrajaya, Malaysia
}

\begin{abstract}
The processing of $\mathrm{TiO}_{2}$ semiconducting materials has a long route with numerous contributing variables. The binder plays an important role in the development of this electro-ceramic material. Higher density and strength of a green body are critical not only for handling at its green state but also to avoid the causes of flaw formation during sintering. Use of appropriate binder can lead to improve characteristics of powder which will reduce density gradient in the green body during compaction. Enhanced green properties can consequently lead to higher fired strength of the varistor discs. The binder system is anticipated to have an influence on the grain growth and microstructure which in turn affect the electrical performance. To investigate this phenomenon, $\mathrm{TiO}_{2}$ powder doped with $0.2 \%$ of $\mathrm{Ta}_{2} \mathrm{O}_{5}$ was processed with and without binder polyvinyl alcohol. The prepared samples were characterized by evaluating the physical properties like green density, fired density, axial and radial shrinkage, micro hardness and compressive strength. It was observed that $\mathrm{TiO}_{2}$ processed with binder exhibited better properties compared to powder processed without binder. The higher percent of binder enhanced the properties further. XRD revealed that the diffraction angle peak was similar to that of pure $\mathrm{TiO}_{2}$. SEM analysis indicated that the average grain size was larger for discs prepared with higher percent of binder. It is anticipated that the larger grain size will improve varistor properties in terms of low voltage applications.
\end{abstract}

Keywords: $\mathrm{TiO}_{2}$; Binder; Physical property; Mechanical property; Grain size; Microstructure

\section{Introduction}

A varistor is a semi-conducting device possessing a non-linear $\mathrm{I}-\mathrm{V}$ characteristic which can provide excellent transient suppression performance. It is a preferred approach to protect the electrical, electronic and power distribution and transmission circuits from destructive voltage levels induced by lightning impulse or switching surges. Currently wide ranges of varistor products like high energy metal oxide varistors, multilayer surface mounted capacitors, industrial high energy metal oxide varistors etc. are available [1-4]. Up to now, $\mathrm{ZnO}$ has been studied most extensively due to its excellent properties to be employed in both the power and semiconductor industry and it has higher nonlinear coefficient than $\mathrm{SiC}$ [5]. However, the recent trends particularly in semiconductor electronics, there are a huge demand for varistors with rather low breakdown voltage and multiple functions [6]. Multilayering, thin foil and thick film method are some of the approaches used by the current researchers to reduce the break-down voltage. Unfortunately, $\mathrm{ZnO}$ varistor is not suitable due to the lack in strength and energy absorption capabilities. The methods used in the production of low voltage application $\mathrm{ZnO}$ varistor are not favorable anymore due to the complexity and high cost. In addition to that, $\mathrm{ZnO}$ varistor exhibits low permittivity and high average breakdown voltage per grain boundary making it rather restricted to be used in low voltage application [7]. On the other hand, $\mathrm{TiO}_{2}$ has been used in various applications such as in beauty products, medicine, aerospace, however, the application as a low voltage breakdown varistor is low due to the fact that dopants and processing aid needed for preparation of $\mathrm{TiO}_{2}$ varistor have not been identified yet.

Varistor is processed by the conventional powder processing route where the additive binder plays an important role. Apart from affecting the powder characteristics, green strength and density gradient of the green cylindrical discs, the grain growth during the sintering process and subsequent microstructure of the varistor are also affected by the binder system. The green and the fired body, homogeneity, grain size, porosity, varistor chemistry are identified to affect the performance of the device remarkably $[8,9]$. In this current research, the investigation of $\mathrm{TiO}_{2}$ ceramic based varistor is performed with the addition of PVA binder as processing aid and $\mathrm{Bi}_{2} \mathrm{O}_{3}$ and $\mathrm{Ta}_{2} \mathrm{O}_{5}$ as dopants. This research is more focused on studying the effect of PVA binder on the properties of $\mathrm{TiO}_{2}$ ceramic based material that would enhance the characteristics for the purpose of low breakdown voltage application. The amount of PVA binder was varied while the composition of $\mathrm{TiO}_{2}$ powder remained unchanged throughout the study. The characterizations and comparison between $\mathrm{TiO}_{2}$ discs processed with and without binder PVA were conducted. It was found that physical and mechanical properties and microstructure were improved with the addition of binder and enhanced further with the increase of binder level.

\section{Experimental Procedure}

The conventional method of ceramic processing was used. Commercially available materials in the form of powder $\mathrm{TiO}_{2}$ (Merck), $\mathrm{Bi}_{2} \mathrm{O}_{3}$ (Aldrich), $\mathrm{Ta}_{2} \mathrm{O}_{5}$ (Aldrich) and binder PVA (Aldrich, 87-90\% hydrolyzed) were used for investigation. The powder was prepared by ball milling with Zirconia $\left(\mathrm{ZrO}_{2}\right)$ balls in an ethanol media. $10 \%$ solution of PVA binder was produced and was added to the slurry during the ball milling process. The prepared slurry was sieved and dried in an oven at $60^{\circ} \mathrm{C}$ for $24 \mathrm{hrs}$. The dried powder was grinded and sieved. Cylindrical discs of $20 \mathrm{~mm}$ diameter were prepared by

*Corresponding author: Shahida Begum, Centre for Advance Materials, Department of Mechanical Engineering, University Tenaga Nasional, Putrajaya, Malaysia, E-mail: Shahida@uniten.edu.my

Received August 07, 2013; Accepted September 12, 2013; Published September 18, 2013

Citation: Begum S, Ansari MNM, Keong LM, Velloo T (2013) Physical Characterization and Microstructure Evaluation of Titanium Dioxide Semiconductor Discs Processed with Binders. J Material Sci Eng 2: 126. doi:10.4172/2169 0022.1000126

Copyright: ( 2013 Begum S, et al. This is an open-access article distributed unde the terms of the Creative Commons Attribution License, which permits unrestricted use, distribution, and reproduction in any medium, provided the original author and source are credited. 
Citation: Begum S, Ansari MNM, Keong LM, Velloo T (2013) Physical Characterization and Microstructure Evaluation of Titanium Dioxide Semiconductor Discs Processed with Binders. J Material Sci Eng 2: 126. doi:10.4172/2169-0022.1000126

using hydraulic press at a pressure of $2.76 \mathrm{MPa}$. The green discs were sintered at temperature of $1350^{\circ} \mathrm{C}$, with a heating and cooling rate of $5^{\circ} \mathrm{C} / \mathrm{min}$ and $10^{\circ} \mathrm{C} / \mathrm{min}$ respectively and with a holding time of 2 hrs. Fired pellets were polished using different grades of SiC paper. Microstructural analysis was conducted by using Scanning Electron Microscope (SEM) of model S-3400N to analyze grain size and the porosity. The samples were coated with Au for SEM. The average grain size was calculated using AGI = line length/number of intercepts. In Table 1, the experimental condition is shown.

\section{Results and Discussion}

The results are based on green and fired density, shrinkage, micro hardness, compressive strength, XRD and SEM analysis. It has been found that the properties were influenced by the addition and variation of the level of binder.

\section{Green density}

The variation of green density with the level of binder is presented in Figure 1. As the percentage of PVA binder increases, the green densities of discs increase as well.

PVA binder acts as a wetting agent that is helpful in rearrangement of grains which eventually led to the elimination of intra-granular porosity in achieving denser packing configuration [10]. The high density of samples prepared from PVA binder is a result of reduction of porosity level and voids in the $\mathrm{TiO}_{2}$ ceramic. Sample $\mathrm{D}$ prepared from $1.6 \%$ PVA obtained the highest density which is $1711.23 \mathrm{~kg} / \mathrm{m}^{3}$.

\section{Fired density}

The effect of PVA binder on sintered density is delineated in Figure 2. As illustrated in Figure 2, the presence of PVA binder significantly influenced the sintered density of the discs. Sample D containing $1.6 \%$ PVA has the highest average density which is $4069.77 \mathrm{~kg} / \mathrm{m}^{3}$. Sintering causes the grains to rearrange which contributes to pores elimination and higher green density led to higher fired density.

\section{Shrinkage}

The effect of addition of PVA binder on axial and radial shrinkage is shown in Figure 3. Results show that, discs processed from $1.0 \%$ PVA have the highest axial shrinkage that is $25.68 \%$. High percentage of shrinkage is caused by the reduction of ceramic voids, thus the level of ceramic porosity decreases resulting in more compact sample. Furthermore, during compaction process, $\mathrm{TiO}_{2}$ particles will tend to slide and rearrange to aid in densification $[9,11]$ where mutual contact between particles occurs due to particles orientation. This suggested that the particle movement is regulated by the binder system of the granules, thus the samples prepared with PVA binder have higher shrinkage than the sample prepared without PVA binder. However, radial shrinkage was higher for discs prepared without binder. It is noted that as the binder content increases, the radial shrinkage decreases. The plasticizing affect of binder reduces frictional force during compaction, causing the force to be distributed evenly. Thus, there will be fewer flaws in compacted green discs which will result

\begin{tabular}{|c|c|c|}
\hline Sample ID & Composition (wt \%) & PVA (wt \%) \\
\hline A & & 0 \\
\hline B & \multirow{2}{*}{$99.3 \% \mathrm{TiO}_{2}+0.5 \% \mathrm{Bi}_{2} \mathrm{O}_{3}+0.2 \% \mathrm{Ta}_{2} \mathrm{O}_{5}$} & 1.0 \\
\hline C & & 1.3 \\
\hline D & & 1.6 \\
\hline
\end{tabular}

Table 1: Composition of powder and binder concentration for experiment.

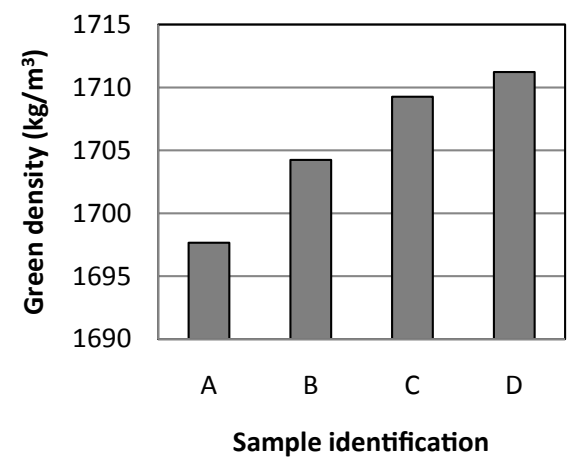

Figure 1: Variation of green density with different percent of binder.

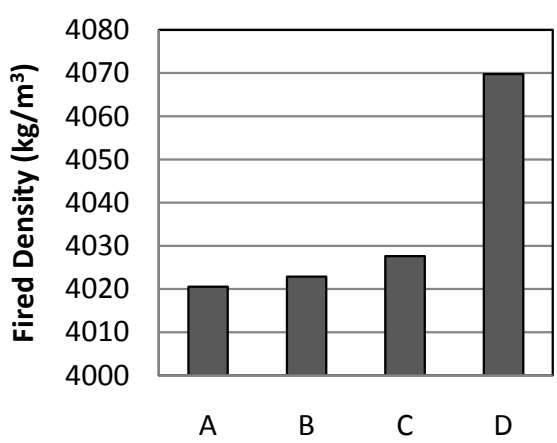

Sample Identification

Figure 2: Variation of fired density with different percent of binder.

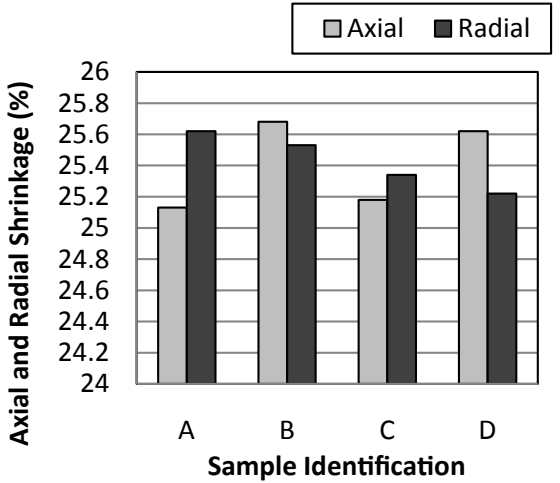

Figure 3: Variation of axial and radial shrinkage with different percent of binder.

in lower radial shrinkage. High sintered density results in low radial shrinkage [12-14] which is directly related to non-uniform packing density.

\section{Mechanical properties}

The effect of binder on the Vickers hardness and compressive strength is shown in Figure 4 and 5. It has been observed that both the hardness and compressive strength increased with increase of binder level which can be associated with higher fired density and less flaws within sintered discs. However, the higher value of hardness and compressive strength for discs without binder may be associated with unknown and unidentified crystalline structures which exist as 
Citation: Begum S, Ansari MNM, Keong LM, Velloo T (2013) Physical Characterization and Microstructure Evaluation of Titanium Dioxide Semiconductor Discs Processed with Binders. J Material Sci Eng 2: 126. doi:10.4172/2169-0022.1000126

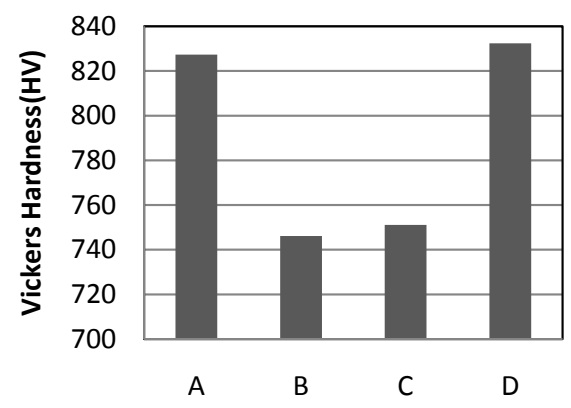

Sample Identification

Figure 4: Variation of hardness with different percent of binder.

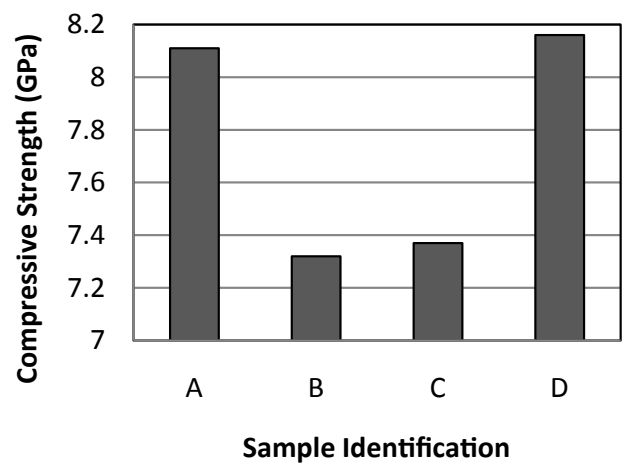

Figure 5: Variation of compressive strength with different percent of binder.

impurities or contaminants as observed in micrograph and smaller average grain size.

\section{Microstructure analysis}

Microstructure was analyzed by Scanning Electron Microscope (SEM) and presented in Figure 6-9. The average grain size was calculated from micrograph and given in Figure 10.

$\mathrm{TiO}_{2}$ discs processed with PVA binder possess a larger grain size compared to $\mathrm{TiO}_{2}$ disc prepared without binder PVA. It can be seen that as the content of PVA binder increases, the grain size increases. Furthermore, based on Figure 6-9, sample A prepared from 0\% PVA shows very visible porosity with various sizes of grains compared to the samples prepared with PVA binder. Porosity elimination is aided by the movement of grain boundaries and grain growth. Thus, increase in the amount of PVA binder led to larger grain growth which contributed to the reduction of porosity and voids. Besides that, by increasing the concentration of PVA binder, the proportion of fine grains decreased due to the formation of stronger bond between the primary grains. These fine grains stuck to cores leading to strong coalescence where it is the fusion of two colliding granules to form a single large granules resulting in rapid granule growth and thus significant increase in growth rate [15]. Sample D prepared with $1.6 \%$ PVA has the largest average grain size whereas, sample A prepared with $0 \%$ PVA has the smallest average grain size.

\section{X-ray diffraction (XRD)}

XRD is a crucial analysis to identify the crystalline phases of a crystalline solid. XRD was performed on the diffractometer operating with $\mathrm{Cu}-\mathrm{Ka}$ radiation at $35 \mathrm{kV}$ and $30 \mathrm{~mA}$ alongside diffracted monochromatic beam with $\lambda=0.1548 \mathrm{~nm}$, using a step scan mode with the step of $0.075^{\circ}$ and $4 \mathrm{~s}$ per step [16]. The diffraction pattern for each sample is presented in Figure 11.

For identification purposes, diffraction patterns are compared manually referring to JCPDS database. Based on the diffraction patterns presented in Figure 11, XRD patterns exhibited distinct diffraction peaks at $27^{\circ}, 36^{\circ}$ and $54^{\circ}$ which are consistent with reference to JCPDS database (No.: 88-1175). Besides that, the diffraction peaks also correspond to crystal planes at (110), (101) and (211) [16] hence, affirming the composition of samples is of pure $\mathrm{TiO}_{2}$. Evidently, sample $\mathrm{C}\left(99.3 \% \mathrm{TiO}_{2}+0.5 \% \mathrm{Bi}_{2} \mathrm{O}_{3}+0.2 \% \mathrm{Ta}_{2} \mathrm{O}_{5}+1.3 \%\right.$ PVA) has the highest intensity counts compared to the other experiment conditions which suggested that sample $\mathrm{C}$ has a greater atomic number which results in higher scattering factor of $\mathrm{TiO}_{2}$. Nonetheless, the XRD results of all the samples have some deviations in intensities as compared to the known reference (JCPDS No.: 88-1175) which implied the occurrence of isostructural phase where the Ti crystals might have similar crystal

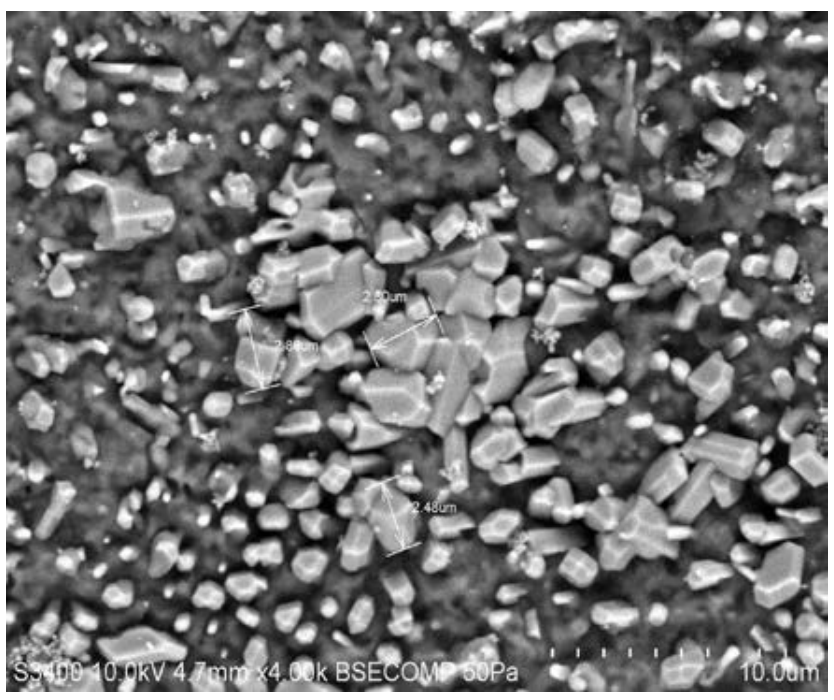

Figure 6: SEM image of disc prepared without binder PVA at $\times 4000$ magnification.

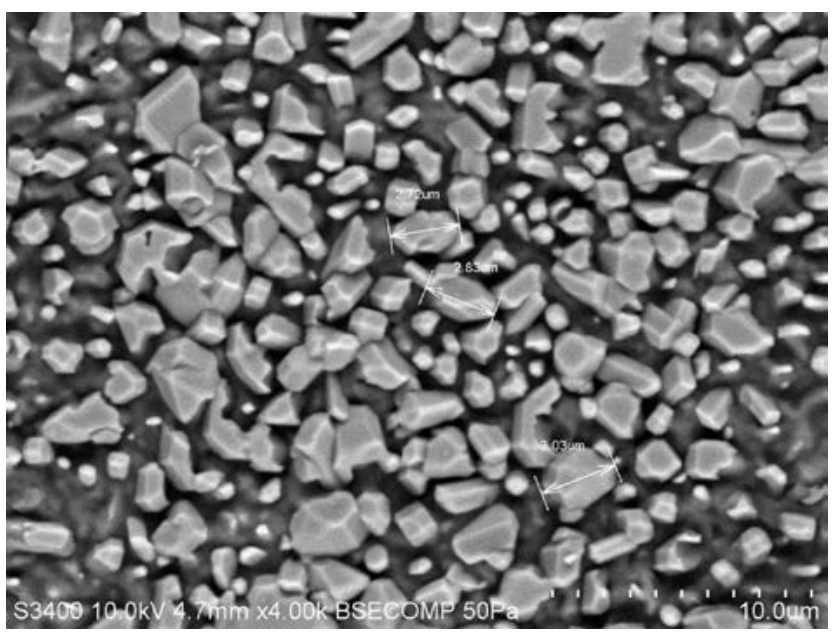

Figure 7: SEM image of disc prepared with 1.0\% PVA at $x 4000$ magnification 
Citation: Begum S, Ansari MNM, Keong LM, Velloo T (2013) Physical Characterization and Microstructure Evaluation of Titanium Dioxide Semiconductor Discs Processed with Binders. J Material Sci Eng 2: 126. doi:10.4172/2169-0022.1000126

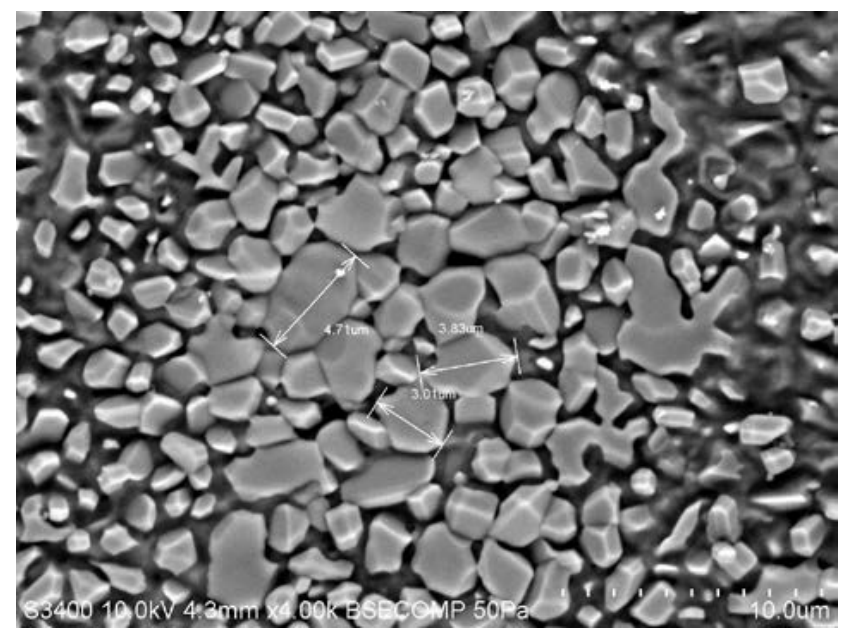

Figure 8: SEM image of disc prepared with 1.3\% PVA at x4000 magnification.

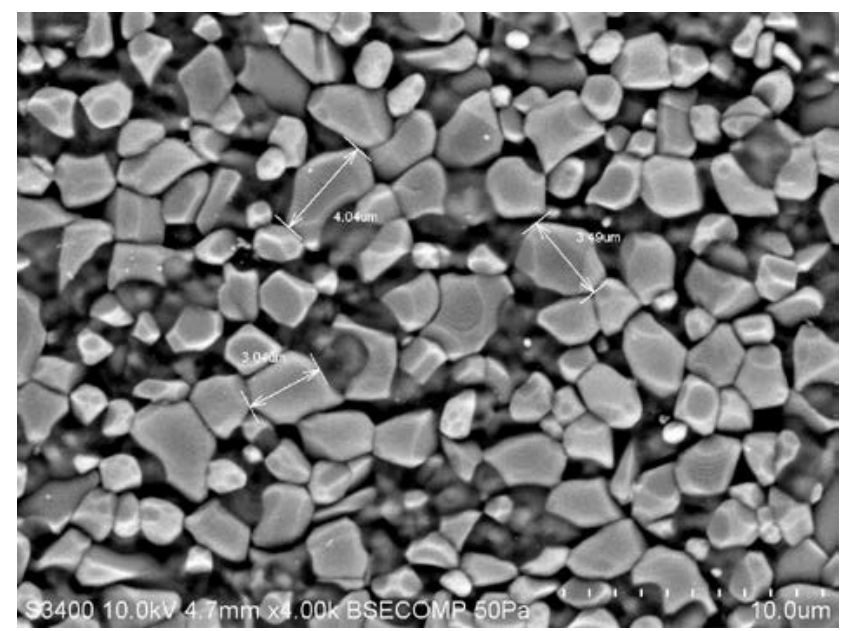

Figure 9: SEM image of disc prepared with $1.6 \%$ PVA at $x 4000$ magnification.

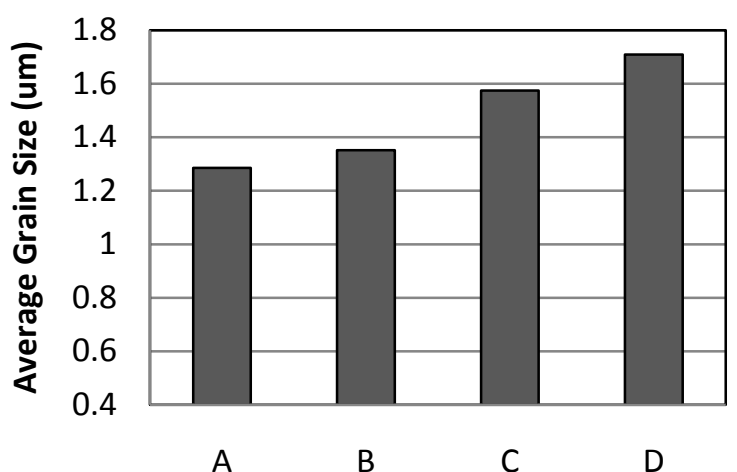

\section{Sample Identification}

Figure 10: Average grain size with different level of PVA

structures but varies in term of atomic number with regards to the cell dimensions and chemical composition $[17,18]$.

Similarly, there are slight deviations of diffraction angle observed in Figure 11 compared to the standard spectrum. These deviations indicated the presence of isostructural phase and thermal expansion of $\mathrm{TiO}_{2}$ crystal structures $[17,18]$. When the samples are exposed to a sudden increase in temperature, the resulted thermal expansion can cause a transition in volume of crystalline solid. As a consequence the thermal shock generated in the $\mathrm{TiO}_{2}$ samples will induce a huge amount of stress. In addition to that, crystal lattice tries to relief itself from the stress by expanding to establish a more stable crystalline structure.

\section{Conclusions}

The physical, mechanical and microstructure of $\mathrm{TiO}_{2}$ powder processed with various level of binder were evaluated. Application of PVA binder in processing of $\mathrm{TiO}_{2}$ discs has secured better characteristics in terms of green and fired density, compressive strength, hardness and average grain size. The green properties of the varistor discs were improved with the use of binder. Enhanced green density was found to be translated into the sintered density, strength and hardness. Axial

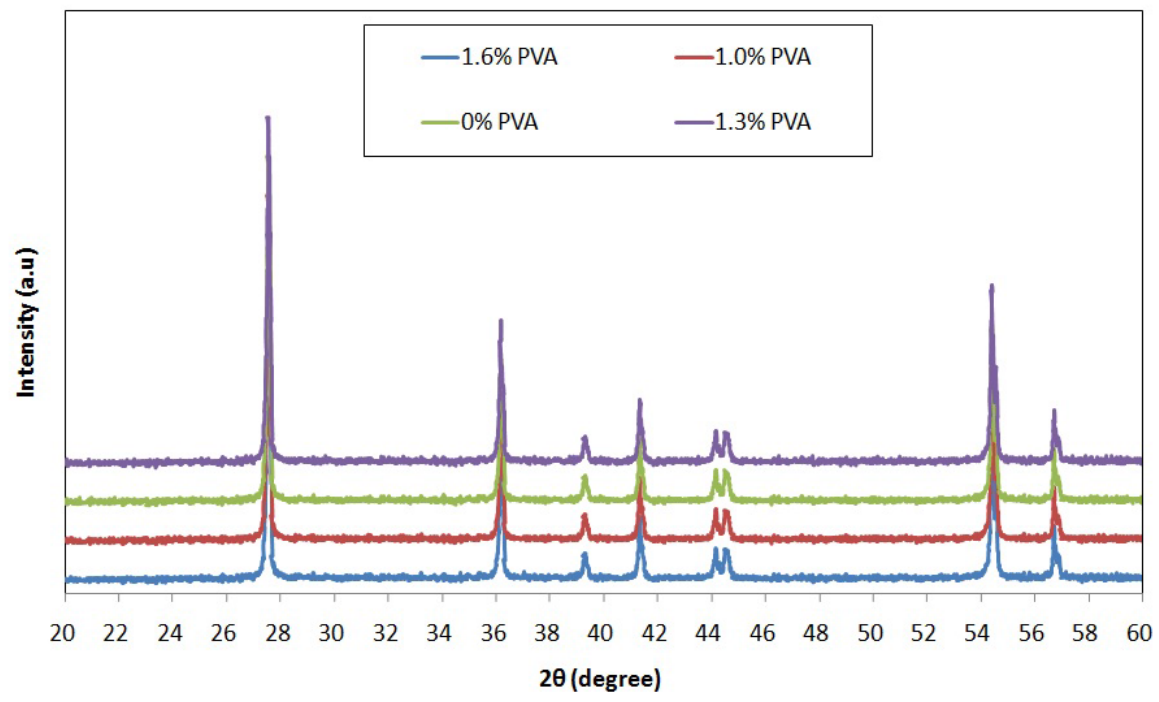

Figure 11: XRD of $\mathrm{TiO}_{2}$ discs prepared with various level of binder PVA. 
Citation: Begum S, Ansari MNM, Keong LM, Velloo T (2013) Physical Characterization and Microstructure Evaluation of Titanium Dioxide Semiconductor Discs Processed with Binders. J Material Sci Eng 2: 126. doi:10.4172/2169-0022.1000126

Page 5 of 5

and radial shrinkage was also affected by the binder level, indicating presence of fewer flaws in the green body during compaction. Moreover, larger grain size and less porosity are anticipated to enhance the performance as a varistor.

\section{Acknowledgement}

The investigation is conducted under the eScience fund of project code 03-02 03-SF0234. The authors acknowledge the financial support provided by Ministry of Science, Technology and Innovation (MOSTI)

\section{References}

1. Matsuoka M (1971) Nonohmic Properties of Zinc Oxide Ceramics. Jpn J Appl Phys 10: 736-746.

2. Gupta TK (1990) Application of Zinc Oxide Varistors. J Am Ceram Soc 73 1817-1840.

3. (1995) Transient Voltage Suppression Devices. Harris Semiconductor, Melbourne, FL, USA.

4. Nahm CW (2012) $\mathrm{Nb}_{2} \mathrm{O}_{5}$ doping effect on electrical properties of $\mathrm{ZnO}-\mathrm{V}_{2} \mathrm{O}_{5}$ $\mathrm{Mn}_{3} \mathrm{O}_{4}$ varistor ceramics. Ceram Int 38: 5281-5285.

5. Fenga $\mathrm{H}$, Penga $Z$, Fub X, Fua $Z$, Wanga $C$, et al. (2010) Effect of $\mathrm{TiO}_{2}$ doping on microstructural and electrical properties of $\mathrm{ZnO}-\mathrm{Pr}_{6} \mathrm{O}_{11}$-based varistor ceramics. J Alloy Compd 497: 304-307.

6. Luo S, Tang Z, Li J, Zhang Z (2008) Effect of $\mathrm{Ta}_{2} \mathrm{O}_{5}$ in (Ca, Si, Ta)-doped $\mathrm{TiO}_{2}$ ceramic varistors. Ceram Int 34: 1345-1347.

7. Li CP, Wang JF, Su WB, Chen HC, Wang YJ, et al. (2003) Effect of Sinter Temperature on the Electrical Properties of $\mathrm{TiO}_{2}$ Based Capacitor-Varistors, Mater Lett 57: 1400-1405.
8. Nies CW, Messing GL (1984) Effect of Glass-Transition Temperature of Polyethylene Glycol-Plasticized Polyvinyl Alcohol on Granule Compaction. J Am Ceram Soc 67: 301-304.

9. Dilima RA, Reed JS (1983) Dependence of Compaction on the Glass Transition Temperature of the Binder Phase. Am Ceram Soc Bull 62: 484-488.

10. Imran ZM, Tanaka S, Uematsu K (2009) Effect of Polyacrylic Acid (PAA) Binder System on Particle Orientation during Dry-Pressing. Powder Technol 196: 133 138.

11. Frey RG, Halloran JW (1984) Compaction Behavior of Spray-Dried Alumina. J Am Ceram Soc 67: 199-203.

12. Hirose N, Asami J (1994) Prediction on Deformation of Fine Powder Green Compact after Sntering by Computer Simulation. J Jpn Soc Powd Powd Metall 41: $1400-1408$.

13. Sung JS, Koo KD, Park JH (1999) Lamination and Sintering Shrinkage Behavio in Multilayered Ceramics. J Am Ceram Soc 82: 537-544.

14. Dimarcello FV, Key PL, Williams JC (1972) Preferred Orientation in $\mathrm{Al}_{2} \mathrm{O}_{3}$ Substrates. J Am Ceram Soc 55: 509-514.

15. http://ethesis.nitrkl.ac.in/4141/

16. Afarani MS, Samimi A, Yekta EB (2013) Synthesis of alumina granules by high shear mixer granulator: Processing and sintering. Powder Technol 237: 32-40.

17. Thamaphat K, Limsuwan $P$, Ngotawornchai B (2008) Phase Characterization of $\mathrm{TiO}_{2}$ Powder by XRD and TEM. Kasetsart J (Nat Sci) 42: 357-361.

18. http://reference.iucr.org/dictionary/Isostructural_crystals 